\title{
ARACOELI CON LOS CINCO SENTIDOS. LA VISTA. ACTUALIDAD DE ELSA MORANTE
}

\author{
ARACOELI WITH YOUR FIVE SENSES. SIGHT. ELSA MORANTE'S \\ PRESENT VALIDITY
}

\author{
Juan Carlos de Miguel y Canuto \\ Universitat de València \\ migueljc@uv.es
}

Fecha de recepción: 14-06-2021

Fecha de aceptación: 15-07-2021

\section{RESUMEN}

Tras recordar algunas de las coordenadas principales de la escritora y, sobre todo, de su novela Aracoeli (1982), se focaliza en el texto un desbordamiento de la realidad directamente relacionado con una alteración perceptiva del narrador-protagonista y también con la deformación de sus recuerdos. Dentro del ámbito sensorial se hace particular hincapié en la vista como médula de tal torsión. Establecer la no fiabilidad del narrador conduce a interrogarse sobre la función del dolor dentro de la obra que, en última instancia, rescata la plena vigencia de Elsa Morante hoy.

Palabras Clave: Aracoeli; Elsa Morante; literatura y experiencia; protagonista-narrador; anamorfosis

\section{ABSTRACT}

After considering the main traits of the author's style, and of her novel Aracoeli (1982) in particular, this article focuses on the text's transcending of reality, which is directly linked to the narrator-protagonist's altered perception, and also to the blurring of his memories. Among the varieties of sensory perception, the article lays emphasis on sight as 
an axis of that evolution. Establishing the narrator's unreliability leads to questioning the role of sorrow in a novel that ultimately confirms Elsa Morante's present validity.

KEY WORDS: Aracoeli; Elsa Morante; literature and experience; protagonist-narrator; anamorphosis

\section{RIASSUNTO}

Dopo aver tracciato alcune delle principali coordinate relative alla scrittrice e soprattutto al suo romanzo Aracoeli (1982), si evidenzia nel testo una sorta di superamento della realtà legato direttamente a un'alterazione percettiva del narratore-protagonista e alla deformazione dei suoi ricordi. Nell'ambito sensoriale si insiste in particolare sulla vista come fulcro di tale torsione. Accertare la non affidabilità del narratore porta a interrogarsi sulla funzione del dolore in un'opera che in ultima istanza riafferma la grande attualità della scrittura di Elsa Morante oggi.

Parole Chiave: Aracoeli; Elsa Morante; letteratura ed esperienza; protagonista-narratore; anamorphosi

La figura de Elsa Morante (1912-1985) sobresale nítidamente en el territorio de la literatura italiana de la segunda mitad del siglo xx. Su voz posee timbres propios, exclusivos, y ha despertado el interés de muchos lectores y estudiosos, envuelto a veces en tintes polémicos. Su marchamo comprende tanto su personalidad como, sobre todo, la singularidad de su escritura, ajena a corrientes dominantes de su tiempo.

Es autora de un corpus principalmente narrativo que incluye un selecto ramillete de novelas: Menzogna e sortilegio (1948), L'isola di Arturo (1957), La storia (1974) y Aracoeli (1982). Las cuatro conforman un tejido bien trenzado. Dirigimos nuestros pasos hacia Aracoeli, título de sonoros ecos latinos: altar del cielo, sí, pero también notable templo cristiano en Roma, amén de nombre propio, circunstanciado con ribetes españoles ${ }^{1}$. Precisamente, de todo el conjunto de las obras morantianas es en esta donde se percibe una huella mayor de la cultura española, plasmada tanto en la lengua empleada (un italiano híbrido de español) como en la materia narrativa misma, visible desde la frase inaugural: «Mia madre era andalusa [...] lei, secondo l'uso spagnolo, portava il doppio cognome Muñoz Muñoz. Di suo nome di battesimo, si chiamava Aracoeli» (MORANTE, 1982: 3$)^{2}$. La fundamental

1 El de Araceli Zambrano, hermana de la española María, y amiga de la autora (cfr. la Introducción de Flavia Cartoni a MORANTE, 2008). El templo es la basílica de Santa Maria in Aracoeli, en el Capitolio. La madre de las hermanas Zambrano también se llamaba Araceli y el cuñado de María era Manuel Muñoz (otra coincidencia nominal), alguien torturado por la Gestapo en Francia y víctima mortal de la policía franquista en España, como oportunamente recuerda Elisa MARTÍNEZ GARRIDO (2016: 181).

2 Además de Aracoeli y familia, también parece que es española la llamada Donna-cammello (pp. 242 y ss.), una prostituta o incluso una madama, que podría emparentarse, aunque sea remotamente, con la pirandelliana Madama Pace de los Sei personaggi in cerca di autore, asimismo de ascendencia hispánica (cfr. DE MIGUEL Y CANUTO, 2020). 
influencia hispánica en el campo del léxico ha sido muy bien aquilatada por Pier Vicenzo Mengaldo:

Si tratta anzittutto del continuo aggallare di parole, frasi, canzoni spagnole alla superficie dell' italiano, constante sovratono espressivo che quasi fiacca le strutture razionali dell'italiano stesso, e lo rende invertebrato: il fenomeno è dunque da valutare nei suoi caratteri ora di ornamentalità ora (e insieme) di vitalismo, ma senza dimenticare il suo significato primo, che è quello di un continuo dissolvimento dell'oggettività nella soggettività, del reale nel fantastico e nell'acutamente affettivo, perché titolare dello spagnolo è, in primo luogo, la folle protagonista, [Aracoeli] con rimbalzi continui sul figlio narrante (MENGALDO, 2000: 163).

Por otra parte, desde un punto de vista biográfico, conviene recordar que, según señala García Melenchón,

Morante emprendió Aracoeli en 1976 y concluyó su primera redacción antes de viajar a España en la Navidad de 1976. Al regreso del viaje inició una segunda redacción que culminaría con la publicación de la novela en 1982, aunque la corrección definitiva se produjo en octubre de 1980. [...] No sabemos con certeza su nivel de español pero es más que probable que tuviera un nivel de compresión pasiva más que suficiente para afrontar la lectura de los textos [españoles] en su poder. (GARCÍA MELENCHÓN, 2006: 39 n.75, 283)

Pero, en realidad, había habido otro viaje anterior a Andalucía, pues como apunta Bernabò, Elsa Morante

Andò in Andalusia due volte: la prima volta nel dicembre 1962, con il giovane amico Allen Midgette; la seconda nel dicembre 1976 con Carlo Cecchi [...]. Certamente in seguito [al segundo viaje] aggiunse alla descrizione [almeriense] vari particolari osservati durante il viaggio. (BERNABÒ, 2012: 245)

Martínez Garrido, por su parte, ha subrayado el valor metafórico de mundo no contaminado, de inocencia primitiva y salvaje atribuible el entorno español y, más específicamente, a Andalucía (MARTÍNEZ GARRIDO, 2016: 175).

La escritura morantiana es exacta, minuciosa, artesanal; el lector percibe una prosa muy elaborada, suntuosa, un esmero extremo, como el que pone un ebanista cuidadoso, aserrando, torneando, encolando, cepillando y barnizando maderas preciadas; el producto final, rematado con el estilo del autor, ya es refinado arte. Es conocido, por otra parte, el máximo cuidado, rayano en lo obsesivo, que la escritora dedicó a la edición de sus textos.

Aracoeli supone, por parte de su autora, la despedida, por todo lo alto, del mundo de la literatura. En la obra cabe rastrear, como trasfondo, un componente autobiográfico (GARBOLI, 1995: 193-200; D’ANGELI, 2003: 16, 61), sobre el que volveremos. Es una novela de ascenso (emocional) y caída, de sufrimiento, frustración y muerte, que temáticamente dinamita uno de los vínculos más sagrados de la vida a ojos de la sociedad occidental, de matriz cristiana: el que une a una madre y a su hijo ${ }^{4}$. Manuele, el personaje protagonista y

3 Para algunos detalles del manuscrito cfr. ZAGRA (1993).

4 Sobre la figura de la madre, omnipresente en la escritura morantiana, cfr. MARTÍNEZ GARRIDO (2016: 173). 
narrador — vástago único de Aracoeli-, ya adulto (a los cuarenta y tres años) emprende, desde Milán, una suerte de peregrinación a los 'santos' lugares maternos ${ }^{5}$ (El Almendral, en Almería, tierra de su madre, fallecida treinta y seis años antes), pero según se van desarrollando las etapas — que discurren por la doble vía del viaje real y, sobre todo, del viaje de los recuerdos- la peregrinación se convierte en un doloroso viacrucis, porque solo encuentra aridez y dolor.

Dentro de un universo obsesivo, neurótico, la evocación del pasado, tras repasar estadios fundacionales e intermedios, arroja el balance del panteón de los dioses familiares arruinado, destruido. Degradada y muerta está la madre — tras haberse convertido involuntariamente en una fuerza arrasadora, (auto)destructiva_-; también fallecido en guerra consta el tío español, Manuel, —mito de heroísmo y virilidad para su sobrino- y reducido a una sombra ha quedado el antaño varonil, admirado y modélico padre, que después igualmente morirá. El viaje real a Almería con destino a una aldea perdida, al final, no dejará de ser un viaje a ninguna parte, porque el verdadero viaje — devastador, obsesivo — ha sido interior, el repaso de la propia vida ${ }^{6}$. Manuele, un fracasado, un homosexual solitario, un ser marginado, pesimista, que desdeña a Dios, sin futuro, que se critica despiadadamente y se compadece de sí mismo, está extraviado en un mundo para él incomprensible, según confesará en varias ocasiones, como en la siguiente, en la que se usa una imagen representativa, de poderosa fuerza expresiva, que plasma cómo él se siente:

Io sono un animale schiacciato sulla schiena da una grossa pietra. Con le zampe disperate raspo la terra, e scorgo al di sopra, mezzo cieco, degli azzurri vapori. Non so perché sono incollato alla terra. Non so quale sostanza siano quei vapori. Non so chi mi ha scaricato addosso la pietra. Non so che animale sono. (MORANTE, 1982: 142-143).

La contrafigura de esta imagen, invertida, aparece en un episodio grotesco, de connotaciones simbólicas, al final del libro, cuando el protagonista, al salir de la morada paterna, en su visita decisiva, encuentra a una anciana baja y obesa, ventruda, accidentalmente caída a tierra, boca arriba, «come una tartaruga capovolta» (MORANTE, 1982: 324), que no para de reír, a la que él, con todas sus fuerzas, no logra levantar.

Si ya en su novela La Storia Elsa Morante había desafiado a las contemporáneas ideologías del progreso, marginándolas de una trama que tiene por protagonistas a gentes humildes de varias generaciones, afligidas por mil sufrimientos sin redención, en Aracoeli la intrahistoria asume toda la primacía con un acontecer íntimo, introspectivo ${ }^{7}$, demorado, de tono especulativo, muy concentrado en un único personaje y su entorno. Incluso la mayoría de las principales claves se concentran asimismo en las primeras páginas, pero los dos protagonistas, madre e hijo, en el relato del narrador, se multiplican como una luz refractada.

\footnotetext{
5 «Simile a un balordo bigotto in pellegrinaggio verso il Santuario del Miracolo», expresión irónica; «Questo mio pellegrinaggio maniaco» (MORANTE, 1982: 20, 25).

6 En un momento de ensoñación, Manuele comprenderá que «in realtà, la corriera de El Almendral mi riporterà a Totetaco», (MORANTE, 1982: 123), lo que equivale a admitir lo quimérico del propósito. «Totetaco», en lenguaje infantil, es Monte Sacro, el barrio de su primer domicilio romano, el de los tiempos felices.

7 «Geniale capacità di introspezione», subraya Bernabò (BERNABÒ, 2016: 260).
} 
No solo están Manuelito niño, que pronto perderá su encanto, y Manuele adulto, están todas las fases intermedias relatadas y todas sus fantasías soñadas. Pero es que en el caso de la madre, en distintas ocasiones, se alude a las varias 'Aracoelis': la prenatal, la de Totetaco, la de $i$ Quartieri Alti, la enferma, la enemiga, la muerta y su proyección póstuma en la mente del narrador, etc. ${ }^{8}$ Aracoeli no deja de ser también un contrapunto de L'isola di Arturo, texto con el que comparte diversos elementos. El más evidente es que ambas novelas están guiadas por un protagonista-narrador autobiográfico ${ }^{9}$ de sexo masculino (que es joven o glosa su pretérita juventud), pero destaca asimismo la pujanza del íntimo vínculo parental, aunque, por supuesto, haya matices diferenciales entre un libro y otro. Sin embargo, lo que en Arturo hay de luminosidad, descubrimiento de un mundo primigenio, paraíso de la naturaleza y aurora de belleza, en Aracoeli se ve eclipsado y se torna oscuridad, derrota vital y pesimismo cósmico.

Ahora bien, desde un punto de vista expresivo, ambas modalidades comparten la creación de universos desbordados, de un subjetivismo extremo, fantasioso e hiperbólico. Mas lo cierto es que, en el nivel compositivo, la autora - que entre medias ha ido variando y madurando su estilo - tiende a emplear fórmulas diferenciadas en cada caso. En Arturo la expresión del esplendor dominante queda confiada principalmente a una adjetivación positiva, auroral, que comunica, entre otras cosas, la maravilla de la naturaleza. Por contra, en el caso de Aracoeli (personaje objeto, sin embargo, en un primer tiempo, de espléndidos elogios) toda la tonalidad oscura, que se plasma también en una adjetivación predominante, pero no exclusiva ${ }^{10}$, no podría producirse sin un marco perceptivo y epistemológico alterado, distorsionado, retorcido, casi expresionista, en el que vamos a fijarnos: el propio de un protagonista más contemplativo que resolutivo, el cual desde el principio se declara «incline alle visioni più che alle indagini» (MORANTE, 1982: 4) $)^{11}$.

Ya en una de las primeras páginas de la novela aparece bien subrayada la dilatación perceptiva de su protagonista, el cual llegará hasta el punto de declararse en posesión de una suerte de sensorialidad añadida, que se superpone a la común y ordinaria de los demás mortales. Esta, a su vez, más adelante se transformará en una hiperestesia. Manuele explica que, en vísperas del viaje a Almería, había experimentado — casi como una llamada - una serie de sensaciones físicas redivivas, trascendentes, ligadas a su madre, que se remontaban a decenios, las cuales comprendían la voz, la respiración y el olor de Aracoeli. Y añade:

\footnotetext{
8 Martínez Garrido ha enfatizado cómo en casi todos los personajes de la novela se da una dicotomía antitética, tanto desde un punto de vista semántico como retórico, de individuos disociados (MARTÍNEZ GARRIDO, 2016: 174).

9 «Io recitante (protagonista e interprete)», propio del novelista moderno, según preconizaba la misma MORANTE (2003: 1505).

10 Destacan los muchos símiles empleados (rasgo ya notado por FORTINI, 1987: 241), que mayoritariamente parecen preservar un cierto candor.

11 A partir de aquí intentaremos desentrañar a Elsa Morante con ayuda de Elsa Morante y específicamente interpretar Aracoeli desde Aracoeli, pues, en tanto que obra singular, crea su propia dinámica semántica. Los mimbres con los que trenzar la lectura de la novela constan en ella misma. Podría ser el método óptimo para superar «la complessità»y «l'inafferrabilità» de las que habla D'ANGELI (2003: 62).
} 
Non so come gli scienziati spieghino l'esistenza, dentro la nostra materia corporale, di questi altri organi di senso occulti, senza corpo visibile, e segregati dagli oggetti; ma pure capaci di udire, di vedere e di ogni sensazione della natura, e anche di altre. Si direbbero forniti di antenne e scandagli. Agiscono in una zona esclusiva dallo spazio, però di movimento ilimitato. E là in quella zona si avvera (almeno finché noi viviamo) la resurrezione carnale dei morti. (MORANTE, 1982: 10) ${ }^{12}$

Más allá de esta indicación, en repetidas ocasiones el narrador nos dará otras de ese marco sensorial exacerbado, turbado, en el que se producen sus vivencias, que ciertamente, al menos una buena parte de ellas, se deslizan desde el plano de la realidad hasta lo puramente imaginario, pues son de naturaleza onírica, visionaria. De alguna manera, podemos decir que conviven una realidad y su réplica imaginaria (su doble), y que, desde luego, ambas se confunden. Ese tipo de hibridismo, con sus propios registros, ya obraba en libros morantianos anteriores, pero ahora, como digo, se tiñe de oscuro y asume el tenor de una insistente deformación perceptiva ${ }^{13}$. La otra cara del fenómeno, complementaria, y asimismo explícita, es la reconstrucción igualmente fantasiosa del pasado, a través de recuerdos también alterados, a los que él mismo se refiere en términos de «rimembranze apocrife» (MORANTE, 1982: 13) ${ }^{14}$. Esta alteración de la memoria — a veces análogamente dilatada, hiperbólica ${ }^{15}$ - conducirá a Manuele a extraviarse en un laberinto de espejos dentro del cual la realidad, una vez más, acaba esfumándose.

En el libro aparecen una serie de escenas clave, algunas de ellas fundacionales, de difícil o improbable verificación, dada su naturaleza de «visiones». Sin ir más lejos, el motor de toda la quête del viaje a España del protagonista es una de ellas, y surge muy tempranamente, tras tener Manuele noticia del incendio, a causa de un bombardeo, del cementerio de Campo Verano, en Roma, donde está enterrada su madre: «nelle mie visioni, quell'ignoto campo mi si rappresentó [...]. Una foresta di fumo e d'incendio, da cui mia madre fuggiva impaurita, sporca di sangue» (MORANTE, 1982: 6). Poco más adelante se pronuncia sobre su futuro personal a través de otra metáfora-visión: «io non vedo altro che un binario storto»,

12 La idea reaparecerá en el texto, al menos parcialmente: «Io solo, però, me n’ero avveduto, per via di quella seconda vista semiconscia che da sempre mi registrava nei sensi ogni moto di lei» (MORANTE, 1982: 205-206). Y no solo se limita a la vista: en ciertas respuestas de su padre, Manuel niño advierte «un filo imperscutabile di reticenza», «per via di un nervo più acuto dell'udito» (MORANTE, 1982: 217).

13 No es asunto que le haya pasado desapercibido a la crítica. C. D'Angeli, a propósito de Aracoeli, ha hablado de «sovversione percettiva» (D’ANGELI, 2003:10). De ella se ocupa también Rebecca WEST (2009: passim); interesa particularmente el concepto que ella utiliza de «anamorphosis» (ibídem).

14 Término de indudable sabor leopardiano. De este tipo de fenómenos se ha ocupado, con cierta amplitud, Holzhey, que les atribuye una función primordial: «The novel not only frequently thematizes the difficulty of distinguishing between different levels of subjective and objective reality and fantasy, but also indicates that this difficulty may be considered as its poetic principle of narration» (HOLZHEY, 2009: 46).

15 «Dicono infatti che i nostri ricordi non possono risalire più indietro del secondo o terzo anno di età; ma quella scena intatta, e quasi immobile, risale a me da più indietro» (MORANTE, 1982: 11). Se refiere a la escena 'fundacional' de su madre dándole el pecho; una suerte de iconográfica «madonna del latte», podemos pensar («quella scena (...) che pareva dipinta», ibídem). Más adelante el narrador distinguirá la memoria del neonato (acaso condicionada por algún tipo de reencarnación) y la memoria adulta (MORANTE, 1982: 111). 
dice, por donde él discurre, «fino a quando sopravviene un urto enorme, ogni traffico cessa», esto es, un golpe definitivo, mortal (MORANTE, 1982: 7).

Otro caso, de alteración de su memoria, es este: cercano a la meta de su viaje, en Gergal (una suerte de pedanía de El Almendral), le sucede que, al contemplar una determinada escena, surge en él un recuerdo, «una rimembranza titubante» (MORANTE, 1982: 139), la experimentación de un dejà $v u$. Él la atribuye a otra vida suya, y pondera: «Può darsi che quell'altra mia biografia sia soltanto immaginaria, un riflesso effimero di questa; ma anche è possibile che questa odierna, invece, sia solo un riflesso dell'altra: la vera» (MORANTE, 1982: 139). Según se comprueba, por esta vía se entra en el mencionado laberinto de espejos replicados, con un fondo de querencia metempsicótica (MORANTE, 1982: 111, 291 y otras). Desde las primeras páginas del libro surge el motivo simbólico del espejo, a partir de la «specchiera», un mueble doméstico que sirve de arranque del pasillo o galería de imágenes que, con sus reflejos, conduce al pasado. Es también la superficie que refleja el propio cuerpo adulto desnudo y rechazado (MORANTE, 1982: 106). Los ojos de la madre eran asimismo el espejo en los que el niño se glorificaba (MORANTE, 1982: 107). Pero diríase que su significado último llegará solo muy al final de la novela, cuando la tía Monda está contemplando cómo le queda un sombrero y el narrador comenta: «La vidi che s'era messa a fissare lo specchio con uno stupore inerme e chiaroveggente, come se quel vetro sciagurato fosse la bocca nera di un tunnel, in fondo al quale non si dava nessuna uscita possibile, se non la morte» (MORANTE, 1982: 316) ${ }^{16}$.

En otro lugar el narrador se interroga sobre las anomalías de su memoria — «una memoria capovolta che ricordava, come già consumate, le mie sorti future? [...] Saranno i sogni a plagiare la veglia, o il contrario? È questo enigma che mi porta, raccontandomi, a confondere l'una con gli altri» (MORANTE, 1982: 210)—, lo que le sumerge en un estado de confusión, como comprobamos, entre sueño y vigilia y, sobre todo, entre pasado y futuro. Por lo demás, esa vertiente fantasiosa de la memoria de Manuel está estimulada, en su caso, por su naturaleza intermitente: un Guadiana que sumerge recuerdos de infancia, los cuales solo aflorarán muchos años más tarde, en la edad adulta, transformados, como se explica, por ejemplo, a continuación, con referencia a la gran mutación sufrida por Aracoeli al final de su vida: «secondo il solito, alcune sequenze e figure [...] oggi mi si proiettano davanti con la forza delle allucinazioni [...]. Per tanti anni si finsero cancellate; e adesso vengono a esibirsi [...]. Che siano, anche queste, finzioni? falsi? scherzi di un trip andato a male? (MORANTE, 1982: 242). La cita del trip, subraya la afición de Manuele al consumo de estupefacientes, factor explicativo que también hay que considerar en este ámbito. Pero no es el único, cuenta también la fantasía infantil: «Spesso, nella testa dei bambini si accampa un genio della trasfigurazione e del arbitrio» (MORANTE, 1982: 255) ${ }^{17}$. Concetta D'Angeli ha esclarecido cómo al trip psicodélico de Manuele, derivado del consumo de alucinógenos se corresponden «alcune descrizioni di paesaggi, la violenza aggressiva e indeterminata dei colori, l'alterazione della percezione acustica, che contribuiscono a fare del viag-

16 Sobre el motivo del espejo, véase también WEST, 2009: 22.

17 Más detalles sobre la «bizzarra condotta della mia memoria» pueden consultarse en MORANTE, 1982: 271. 
gio di Manuele una sequela di incontri terrorizanti e un doloroso dibattersi in luoghi ostili e minacciosi» (D'ANGELI, 2012: 31).

Por otra parte, los contenidos de una memoria fantasiosa o caprichosa se aproximan mucho a los productos de la imaginación, pero proyectada hacia el pasado, hasta el punto de resultar equivalentes ${ }^{18}$. De hecho, es el narrador quien habla de «ricostruzioni visionarie»: «Nel suo lavoro continuo, la macchina inquieta del mio cervello è capace di fabbricarmi delle ricostruzioni visionarie - a volte remote e fitizie come morgane, e a volte prossime e possessive, al punto che io m'incarno in loro» (MORANTE, 1982: 11). Sobre la riqueza de la imaginación también se pronuncia el narrador: «L'immaginazione è uno strumento multiplo e imprevedibile, che al solo tocco di una corda può rendere diverse strane vibrazioni» (MORANTE, 1982: 283), imaginación que a veces conduce al delirio. Y él mismo llegará a hablar de «la mia vista mentale», para referirse precisamente a golpes oflashes imaginarios (MORANTE, 1982: 25).

De los cinco sentidos que son la base de nuestra experiencia material del mundo, el primordial es el de la vista. En una situación de precariedad extrema, el ser humano podría postergar o prescindir de los otros cuatro y quedarse solo con este ${ }^{19}$. Ver equivale a vivir: «mientras yo viva y tenga los ojos abiertos sobre la tierra» proclama Aquiles a Calcante, en el arranque de la Ilíada, reconfortándole y asegurándole que nadie pondrá sus «manos pesadas» sobre él (Iliada, I, vv. 88-89). Análogamente, en el mismo poema, dejar de ver equivale a morir: «la oscuridad cubrió sus ojos» es la frecuente fórmula empleada para designar a la muerte (III, v. 526, passim). En no pocas ocasiones, a lo largo de Aracoeli, el narrador-protagonista insiste en apelar a la vista, ese «solito nervo primordiale» ${ }^{20}$ (MORANTE, 1982: 236) y específicamente subraya la precariedad de la suya. Pero, en realidad, como él mismo nos hace saber, esa limitación está ligada a una prodigalidad que apunta en una dirección muy distinta: «Per uno dei suoi soliti effetti bizzarri, la mia vista malata, mentre mi stringe e impoverisce il mondo aperto, è capace di suscitarmi, a occhi chiusi, luci e spettacoli straordinari» (MORANTE, 1982: 110) ${ }^{21}$. La mencionada precariedad aparece compensada, hasta cierto punto, por la incorporación de unas gafas, ya de niño. A este respecto hay que valorar todo el amplio desarrollo de este tema, que llega a constituir un microcosmos dentro del relato ${ }^{22}$. A este respecto, el punto álgido se alcanza cuando Manuelito, lleno de miedo, se encuentra frente a la Quinta-burdel en la que cree que se ha acogido su madre, huida de casa, a la que él ha ido a buscar; la sugestión, sin duda, obra la metamorfosis: «Un occulto lavoro di tecnica spettrale aveva trasformato i vetri dei miei

18 «La fantasia mi figuraba le grandi Sorelle della Moda [las modistas que servían a Aracoeli] quali appartenenti tutte a una specie di Ordine misterico» (MORANTE, 1982: 180).

19 Aunque existe cierta polémica sobre si oír podría ser más imprescindible que ver. Es conocido el juicio de André Gide, establecido en su Journal des Faux-monnayeurs, en el que, perorando a propósito de la creación de los personajes novelescos, escribe: «Je crois que je perdrais moins, perdant la vue, que perdant l'ouïe» (GIDE, 2009: 552). En cambio, para Manuele la jerarquía parece ser la inversa.

20 Veamos este otro ejemplo en el que también se la involucra: «Si dice fra la gente che gli sposi delle adultere sono spesso ciechi alla propria disgrazia. [...] Può darsi che l'apparente cecità di lui gli provenisse di una antica veggenza, più fonda e tragica della veduta esteriore» (MORANTE, 1982: 250).

21 Y sigue: «specie quando il mio cervello è confuso - gli oggetti comuni mi si tramutano in sagome stravaganti e indecifrabili» (MORANTE, 1982: 20).

22 De él se ocupa, entre otros, West, que toma en consideración, necesariamente, el conocido relato de Anna Maria Ortese «Un paio di occhiali», incluido en Il mare non bagna Napoli, 1953, (WEST, 2009: 20 ss). 
occhiali in piccoli prismi ottici: attraverso i quali la luce mi si scomponeva in filamenti convulsi e mutanti, dal violetto al purpureo, all'oro cupo» (MORANTE, 1982: 277).

El protagonista adulto, a conciencia, a veces opta por quitarse las gafas, sabedor de que entonces «il mondo circostante ai miei occhi semiciechi [...], si scioglie, [...] in un brulicame acquoso, corso da luci stralunate e immagini storpie» (MORANTE, 1982: 23) ${ }^{23}$. Es lo que le sucede, por ejemplo, en un rincón del aeropuerto de Madrid, cuando a su ver todo se deforma y observa que «passa una signora obesa con due teste» y ante una serie de hombres alineados, le parece que «al posto della faccia hanno una proboscide» (MORANTE, 1982: 23). Manuel, por otra parte, se sabe poseedor de una capacidad sensitiva extra en relación con su madre. De esta manera, cuando estalla el conflicto de ella con Zaira, él manifiesta ser el único en la casa que lo había intuido, «per via di quella seconda vista semisconscia che da sempre mi registrava nei sensi ogni moto di lei» (MORANTE, 1982: 205-206). Y en su citada visita solitaria a la Quinta, el narrador-protagonista muestra tener plena conciencia de la alteración experimentada por su vista: «Ma poco importa quello che potei vedere in realtà, se il mio senso era intriso degli amati succhi materni, allucinanti, quanto l'erba magica» (MORANTE, 1982: 277). En todo caso, el sentido de la vista, los ojos de los personajes, adquieren gran relevancia, hasta el punto de que, por ejemplo, en otra ocasión, ya en la etapa familiar crítica, reunidos los tres miembros en torno a una mesa, toda la tensión latente y la disparidad de sus vivencias interiores se expresa exclusivamente por medio de un juego de miradas, que transmiten incomunicación:

Io sempre tenevo gli occhi levati verso di lei, in una implorazione incessante senza risposta; finché la sua faccia — a forza di guardarla — sembrava disfarmisi davanti come una nube; mentre il suo sguardo amante e sperso pellegrinava intorno a mio padre, sostando ogni tanto a mirarlo con una acutezza acerba e disperata, come l'unica stazione del suo cuore. Parve a un certo punto, da come lo riguardava nel volto, attaccandosi con le pupille alla sua forma, che volesse imprimergli sui tratti un proprio stigma dolorante. D'improvviso poi spalancò gli occhi su di me; però senza indugio li richiuse (MORANTE, 1982: 265).

El círculo sensitivo-visual, según ya he mencionado, se cierra cuando tomamos en cuenta la memoria, que - como suele afirmarse - no deja de representar los ojos del pasado, y que a menudo funciona por imágenes ${ }^{24}$. Ambos factores apuntan, pues, al triunfo de la fantasía ${ }^{25}$. De hecho, en la novela, el punto máximo de excitación perceptiva se da cuando se cruzan la dilatación visual y la alteración de la memoria, fecundándose recíprocamente. Ello sucede, por ejemplo, a propósito de la remembranza de un simulacro de

23 «L'inettitudine a vedere il mondo con chiarezza è la forma esterna di una inadeguatezza interpretativa» (D’ANGELI, 2003: 65).

24 Véase este ejemplo que corresponde al episodio, preadolescente, partisano, evocado por el narrador adulto: «Tutte le sequenze, una a una, sono rimaste fotografate, a quell'ora nel mio cervello»; «Rivedo, in un pomeriggio domenicale, me stesso seduto» (MORANTE, 1982: 150, 177).

25 La fantasía es ingrediente narrativo bien apreciado y explicado por Morante, asimismo estudiado por Flavia Cartoni (1999). Ella la cataloga en trece subespecies, tras analizar sus cuatro novelas citadas, considerando tanto el yo narrador como el yo narrado. Entre ellas nos interesan: «Deformazione della realtà nella costruzione mentale. [...]. Allucinazione auditiva. Allucinazione visiva. Apparizione di persone, visione de immagini. Sdoppiamento di persone, sia del personaggio narrato, sia di altri personaggi della narrazione» (CARTONI, 2015: 31). 
juicio sufrido por Manuele de preadolescente, cuando, en tiempo de guerra, pretendió ser aceptado por dos jóvenes que vagaban por la montaña, a los que él creía jefes [Capi] de una guerrilla partisana. Ante ambos «jueces» él permaneció vendado, pero desde el presente del narrador, la evocación (de cariz monstruoso) es esta:

Io ricordo (come fosse vero) che i miei occhi, per quanto acceccati dalla benda, d'un tratto VIDERO la scena [...] come attraverso un binocolo rovesciato. Ci si vedeva una coltre, [...] e sopra $[\ldots]$ i due «Capi»; i quali tuttavia non erano più due, ma uno, con un paio di teste e quattro gambe [...]. E quell'ibrida criatura si torceva in una smania forsennata, fra il tripudio e l'agonia (MORANTE, 1982: 166). ${ }^{26}$

Cuando, tras la pérdida de la hija neonata Carina, comienza la metamorfosis física y psicológica de Aracoeli —un momento clave en la historia— Manuele refiere el estupor vivido por él, subrayando precisamente que sus percepciones visuales (en el pasado infantil y en el presente adulto) lo transportan a una contemplación de ella a caballo entre el desdoblamiento y la mudanza del sujeto:

Mi succedeva di $[\ldots]$ guardarla con occhio stupito e malcerto, ma sempre soggiogato dalle sue trasmutazioni. Ora, essa mi si sdoppiava in suo fratello Manuel. Ora mi tornava alla prima Aracoeli di Totetaco. E in altri momenti mi si straniava in una forma incognita [...] minata da una lebbra della natura. In quei momenti - se la riguardo adesso [...]. Aracoeli! così ti guardavo allora [...] e così ti guardo ancora adesso [...] (MORANTE, 1982: 235 $)^{27}$

Es decir, que, en síntesis, hay una convergencia entre lo que el propio narrador denomina «la macchina dei ricordi»y «la macchina dei sensi» (MORANTE, 1982: 111, 199) ${ }^{28}$.

Se ha de considerar que buena parte de las vivencias narradas por Manuele corresponden a su infancia. Podemos decir, pues, que el protagonista de muchas de las páginas es un niño, Manuelito. Su perspectiva, aunque luego pueda ser enmendada por su ser adulto, es peculiar, pues en muchos momentos no deja de poseer las limitaciones propias de su edad. Carece de la experiencia y desarrollo suficientes para descifrar cabalmente cuanto percibe: «Ma in quell'ora, purtroppo, il mio cervello diminutivo non sapeva leggere le sue proprie fotografie» (MORANTE, 1982: 150), informa el protagonista a propósito del citado episodio partisano, en edad escolar. Y más adelante detalla más esa mecánica de enmienda empleada por el narrador:

Certe mie rievocazioni odierne non si fondano, certo, sulla testimonianza dell'ignaro pischelletto ch'io ero a quell'età. [...] tento di leggere il passato come un indovino legge il futuro

26 Otra modalidad se comprueba en este otro ejemplo, que surge al final de la novela, cuando, tras visitar a su padre, Manuele sale a la calle y, como deslumbrado, sufre una alucinación: «Anche i passanti [...] mi si deformarono in brutte bambole di carta, o sagome animate da un artificio. Ma quando ebbi, da lì a poco, la facoltà di guardare, la scena della realtà mi sbigottí peggio ancora della mia visione falsa» (MORANTE, 1982: 325).

27 La mirada será esencial en la última etapa, animalesca, patológica, de Aracoeli, en sus operaciones de seducción asilvestrada de extraños: «È venuto il tempo che in strada, essa non soltanto si lascia guardare dagli uomini ma li guarda. I suoi sguardi sono di una impudizia atroce» (MORANTE, 1982: 245).

28 Esta última, se explica en el texto, en realidad está ligada al servilismo del hombre mortal —expulsado del paraíso- sobre la tierra. La inmortalidad, propia de los dioses, comporta lo unitario, una integralidad en la que no son necesarias las distinciones: «I nostri organi di senso in realtà sono delle mutilazioni» (MORANTE, 1982: 199). 
[...] quest'ottica visionaria [...] rimane pure, in qualche modo regolata dallo spirito infantile che [mi] circoscriveva, allora. (MORANTE, 1982: 192)

Sabemos incluso que a menudo, cuando tienen miedo, los niños cierran los ojos, para evitar la realidad. De hecho, Manuelino, con frecuencia, efectúa el gesto, equivalente, de quitarse a propósito las gafas (en principio porque siente que le afean). Análogamente, en un momento extremo de la crisis materna, que involucra a su hasta entonces amado Daniel, Manuelito, encerrado en su habitación, reacciona así: «Mi premetti le mani contro gli orecchi per non ascoltare» (MORANTE, 1982: 262). Merece destacarse asimismo la escena en la que, como una suerte de pudorosa autocensura, se quita las gafas para no ver a su madre envuelta en complicidades eróticas con un nadador (MORANTE, 1982: 244). Poco antes, sin ellas, la busca con la mirada dentro del mar y la descripción de lo que percibe de nuevo tiende a lo grotesco: «vedo lo spazio marino spalancarsi in una dismisura vorace, confusa e rutilante $[\ldots]$ in questa piena mostruosa. Vi si aggrovigliano stelle filanti, vermi fosforescenti e serpi di fuoco; e vi galleggiano occhi di annegati, putrescenze iridate e squame [...]» (MORANTE, 1982: 243-244). Semejante «autocensura», pero en edad ya más crecida, la ejercerá en el ámbito de otra escena de acoplamiento sexual, que igualmente presenciará, aunque haya sido narrada con anterioridad (MORANTE, 1982: 70). El principio general que sobrevuela todos estos casos lo enuncia, muy al principio, Manuele adulto en términos eufemísticos: «con un gesto automatico mi sono tolto gli occhiali, come uso abitualmente quando non c'è nulla che m'importa di vedere» (MORANTE, 1982: 18).

En conjunto, pues, la de Manuelino no deja de ser una perspectiva distorsionada, distinta, pero equiparable en este aspecto a la del adulto de las restantes páginas ${ }^{29}$. En ocasiones el narrador, confundido, no consigue ir más allá de una conjetura, como sucede al rememorar el episodio de su lactancia tardía: «di quelle poche ore mi torna solo qualche parvenza fugitiva, dubbiosa fra la veglia e il semi-delirio. Cosí, non saprei se fu vero o illusorio...» (MORANTE, 1982: 209). Curiosamente, un poco más adelante, el narrador rectifica, la escena había sido real, no soñada: «però i sogni che ne germinarono vennero a innestarsi sulla sua sostanza [...]; e a momenti io supponevo che quella scena appartenesse al mondo delle ombre, e non dei corpi; così come alle sue concrescenze oniriche prestavo la natura dei corpi materiali» (MORANTE, 1982: 210).

Todo ello nos lleva a considerar que, en el plano cognitivo, toda la narración se inclina hacia una vertiente fantasiosa y el corolario es que la fiabilidad del narrador queda en entredicho. Hasta el propio protagonista, en un desahogo, llegará a proclamar que se engaña a sí mismo: «io baravo con me stesso [...] questa sorta de monologo sregolato, che vado qui recitando a me stesso, io l'ho imbastito, fino dall'esordio, coi fili dell'equivoco e dell'impostura [...] io vado raccontando a me stesso favolette parrocchiali» (MORANTE, 1982: 24) ${ }^{30}$. Está claro que, en principio, toda novela es una obra de invención por parte de quien la ha creado,

29 La deformación perceptiva del sujeto incluye la visión deformada que Manuele tiene de sí mismo ante el espejo. A este propósito Franco Fortini la ha parangonado con los retratos de F. Bacon (1987: 243).

30 Stellardi explícitamente apunta al «aura di radicale e confessata inaffidabilità che avvolge la narrazione e il narratore» (2014: 187). 
pero otra cosa es que su narrador-protagonista perciba la realidad alterada, la confunda incluso con el sueño ${ }^{31}$, y que, de alguna manera, la invente. Podría decirse que Manuele es un adulto aferrado a su infancia, alguien que, a partir de un trauma familiar, sufrido de niño, se ha bloqueado emotivamente, no ha acabado de madurar. Por ello no está en condiciones de ver lúcidamente, de asumir el mundo e interactuar con él ni de contárnoslo ${ }^{32}$. En este aspecto podría ser considerado, a su manera, un «inetto» más de la literatura italiana ${ }^{33}$.

Será el propio narrador el que basculará sobre su fiabilidad y hablará de «testimonianza infida» en un párrafo en que vuelve a explicarnos la mecánica paradójica de su memoria (una «bizzarra condotta») que rescata del profundo pasado y del olvido una serie de «gesti e movenze e particolari minimi» $y$, sin embargo, posterga «i pochi ricordi coscienti che già me ne segnalavano i passaggi e le svolte, e che sempre dal punto del loro scoccare, hanno marcato di certeza la mia testimonianza infida»(subrayamos), (MORANTE, 1982: 271) ${ }^{34}$. Y mucho más tajante - y nihilista - se mostrará en uno de los párrafos conclusivos del libro: «E so già che la mia presente analisi [de su llanto] e i suoi pretesi risultati sono immaginari, come immaginaria, del resto, è l'intera mia storia (e tutte le altre storie, o Storie, mortali o immortali)» (MORANTE, 1982: 327).

Muchos de los — confusos - recuerdos de su infancia, testimonio de los extravíos últimos de su madre, Manuele los ha mantenido preservados en exclusiva para sí, porque en su momento, pese a no acabar de entenderlos, era consciente de que «dovevano restare un altro segreto mio proprio, da non dire a nessuno al mondo» (MORANTE, 1982: 246). Y ello lleva al narrador presente, en el acto de su desvelamiento, a justificarse: «E in realtà solo oggi, che li riscopro, io ne parlo: sapendo poi che, tanto, ne parlo a vuoto» (MORANTE, 1982: 246). Esta confesión de soledad, una vez más ratificada, pone en evidencia, por otra parte, que todo el libro es una suerte de monólogo introspectivo ${ }^{35}$, que tiende a la confesión, de un yo fracturado, sin ningún destinatario externo (más allá de sí mismo). Como si fuera un grito ahogado en medio del desierto. Curiosamente Manuele califica el modo de expresarse de su rígida abuela piamontesa (un auténtico «vaniloquio») de «soliloquio ininterrotto e ripetitivo trafelato a rincorrere se stesso in un labirinto», pero este es un juicio que bien podría aplicárselo a sí mismo (MORANTE, 1982: 288). De hecho, es en ese tiempo, en completa ausencia de su madre - cuando no le es posible ningún tipo de comunicación (afectiva) con ella - cuando empiezan su auténtica soledad y su definitiva introspección:

31 «Io sono stato sempre una fabbrica enorme di sogni» (MORANTE, 1982: 291).

32 «La tua morte tempestiva, nell'amputarmi da te, ha sbarrato la mia crescita, affinché la mia-tua invenzione bambina si serbasse immune eternamente dalla ragione» (MORANTE, 1982: 289).

33 Así lo considera también Ebru Sarikaya (2017: 59).

34 Incluso en algún otro lugar profundiza en el funcionamiento de su memoria: «Quell'ultima estate [con Aracoeli viva] mi riappare adesso come una pestilenza: dove la serie ossessiva dei fenomeni si accumula, a riesumarla, in una concrezione pullulante su cui si accampa qualche scena singola, che tende a figurare in sè la serie entera» (MORANTE, 1982: 237).

35 »Mi sono ridotto [...] a una solitudine tale, da non avere altri interlocutori che me stesso», señala el narrador cuando informa de los debates consigo mismo «a più voci, sebbene, in realtà, la voce fosse una sola: la mia» como preámbulo a la trascripción del proceso a sí mismo, en el que se desdobla en varios papeles (MORANTE, 1982: 113, 114-118). 
«Io non potevo scambiare domande e risposte se non col solo mestesso. E dubbi persecutori si scontravano dentro la mia testa come reclusi in una galera» (MORANTE, 1982: 246). Con todo, aparentemente, sí hay un destinatario interno: su madre, Aracoeli, ¿quién si no? A ella, en vocativo, dirige su monólogo en contadas ocasiones, alguien ya muerta años atrás (MORANTE, 1982: 100-105 — largo discurso reprobatorio-, 107, 289, 291, etc.). ${ }^{36}$

El pesimismo que exhala la novela, la carga negativa contenida en su historia, de alguna manera había sido anticipada muchos años antes en un juicio de la propia autora incluido en Pro o contro la bomba atomica, un conocido texto hecho público por vez primera en 1965. Allí se lee:

La grande arte nella sua profondità è sempre pessimistica per ragione che la sostanza reale della vita è tragica. [...] Il movimento della vita è segnato dagli incontri e dalle opposizioni, dagli accoppiamenti e dalle stragi. Nessuna persona umana rimane esclusa dall'esperienza del sesso, dell'angoscia, della contraddizione e della deformazione. [...]. La purezza dell'arte non consiste nello scansare quei moti della natura che la legge sociale [...] censura come perversi o immondi; ma nel riaccoglierli spontaneamente alla dimensione reale, dove si riconoscono naturali e quindi innocenti» (MORANTE, 2003: 1546-1547).

Obsérvese que el sexo aparece en primer término como parte de esa sustancia trágica de la vida. Su visión negativa es un eje primordial de esta obra: la enfermedad conduce a Aracoeli a un degradante furor sexual y la homosexualidad de Manuele lo arrincona y lo humilla. No es signo de vida, es signo de postración y muerte. Como decíamos, ateniéndonos a las leyes de la ficción narrativa, nos damos cuenta de que toda la trama referida por el narrador cuenta con un grado — no determinado- de infidelidad ${ }^{37}$. Y de discontinuidad. Percibimos que se alternan y se entrecruzan tramos sólidos que informan limpiamente de variados episodios biográficos — con un yo metamórfico-, y tramos líquidos, a menudo algo más confusos y recargados, en los que el narrador protagonista mezcla sensaciones y cabalga volubles estados de conciencia ${ }^{38}$. El correlato lo constituye la alternancia entre páginas de una modalización narrativa más «limpia» y tradicional y otras en las que nos aproximamos a los vericuetos de una conciencia, más resbaladizos ${ }^{39}$.

En conjunto, podemos suponer que muchos de los detalles trasmitidos no corresponden fidedignamente a lo que en la «realidad» pudo suceder, que la historia que hemos conocido es aproximada, que incluso está fabulada por su relator, fecundada por su fantasía, la de alguien que tiende a entregarse al sueño y que a menudo deambula entre el mundo de los vivos y el vacío de los muertos ${ }^{40}$. Ello no empece en absoluto la calidad narrativa, simplemente determina su status. Ahora bien, permaneciendo dentro de la fictio narrativa, a

36 Hay algún otro vocativo ocasional, como el dirigido al caudillo Franco (MORANTE, 1982: 19).

37 Holzhey usa el término «unreliability» (2009: 41).

38 Holzhey aprecia también diferencias entre dos partes de la obra: «more ordered and cohesive narrative of the book's second half» (2009: 43).

39 D'Angeli habla de «romanzo fluido e senza struttura» (2003: 67).

40 Según Fortini, «sogni, immaginazioni, fantasticherie, premonizioni, allucinazioni, dejà vue e simili, interfoliano tutto il romanzo e sono [...] lo specchio che àltera o svela l'ordigno ermeneutico [...] [che] dispone [...] a penetrare nell'Altra parte, reame dei morti e dell'eterna ripetizione» (1987: 241-242). 
diferencia de los hechos relatados, de su contorno, de lo que no cabe dudar es de la autenticidad de los sentimientos expresados en primera persona. Cuando el protagonista nos expone su claudicación ante el mundo y nos habla de su precariedad afectiva, de su infelicidad, de su duradera falta de amor, que arranca desde la quiebra de su vínculo con Aracoeli, en su infancia, no tenemos por qué cuestionarlo ${ }^{41}$. Aquí no cuenta lo factual, los nudos de la trama, sus detalles, aquí cuenta lo emotivo, lo vital. Y la huella de la ofensa, de la humillación y el dolor, su recuerdo, lo sabe cualquier ser humano, es indeleble, no se nos mezcla y confunde en la memoria con otras sensaciones de otra naturaleza, es decir, perdura ${ }^{42}$. (A lo sumo, por supervivencia, la conciencia puede llegar a extirparla, como un cirujano) ${ }^{43}$.

\section{CONCLUSIONES}

Un niño está enamorado de su joven madre, la encuentra bellísima, y al mismo tiempo admira a su padre, un militar viril, íntegro, respetado por los demás. Este puede ser el universo de muchos infantes, los cimientos sobre los que edificar una existencia adulta equilibrada, plena, más allá de las acechanzas que pueda depararle el discurrir de la vida. Sin embargo, a temprana edad, la senda de Manuele se interrumpe, sufre un shock, vive una ruptura traumática: la dramática deserción (/pérdida) de su madre, a la que sucede la ruina - física, psicológica — de su padre. Para él se ha quebrado la armonía primaria del mundo. A partir de entonces su vida será un errar sin rumbo, sin destino, sin consuelo. No podrá reponerse. A falta de una maduración emocional en el entorno familiar, no ha aprendido a desenvolverse con los demás. Llegada ya la edad adulta, ante su fracaso vital, se plantea una meta regresiva, un intento vano de recuperación de la madre, «atravesando las fronteras del tiempo y del espacio» (MARTÍNEZ GARRIDO, 2016: 185) en alguna ignota dimensión — viajando a su entorno vital primigenio, en Almería-, a partir del cual acaso recuperarse y volver a emprender su camino. Pero ello, con estos antecedentes, naturalmente, resultará imposible ${ }^{44}$. Razonando por contigüidad en el binomio individuo-sociedad, en el plano interpretativo, podemos descifrar esa fábula ${ }^{45}$ como una imagen que muestra la rup-

41 Como indica Holzhey, «the large majority of Manuel's memories seems to be painful and therefore at first sight more credible» (2009: 46).

42 Esto lo asume incluso -implícitamente- el propio texto, por ejemplo: «Di quel mese di vacanza non ricordo nulla, se non la mia nostalgia della presenza materna, e l'antipatia che mi fu decretata [...] dai figli dei miei ospiti» (MORANTE, 1982: 195). Entonces Manuelito había sido apartado de su hogar porque su madre estaba a punto de dar a luz.

43 Más limitadamente, lo enuncia el propio narrador: «Accade, per leggi naturali, che certe esperienze fuori di misura, consumate da un io troppo bambino, poi si rigettano dallo stesso bambino in crescita [...]» (MORANTE, 1982: 303).

${ }^{44}$ La tristeza de la parábola biográfica de Manuele y, pese a ello, su permanencia en el mundo, también puede explicarse desde los clásicos. Retomemos la Ilíada y recordemos, por un lado, el parlamento de Zeus ante la pérdida de Patroclo: «Pues nada hay sin duda más mísero que el hombre/de todo cuanto camina y respira sobre la tierra» (XVII, vv. 446-447) y, por otro, las palabras de Febo en torno a la muerte y a las penas de familiares y allegados del difunto: «Pues las Moiras han hecho el ánimo humano apto para soportar» (XXIV, v. 49).

45 Elsa Morante, como sabemos, estaba muy avezada, desde su juventud, en la composición de fábulas. Muchas de ellas se recogieron en el libro Il gioco segreto (1941), que no quiso volver a publicar. 
tura de la armonía social (ya a la altura de los años de la bomba atómica) que mantiene al mundo en un devenir errático, donde hay felices pocos y, como Manuele, infelices mu$\operatorname{chos}^{46}$. Y ese extravío se expresa también a través de las inseguridades, los tumbos y las alucinaciones del narrador.

Por otro lado, en nuestros días, en el arranque de la tercera década del siglo XxI, cuarenta años después de que fuera publicada, podemos preguntarnos qué lectura cabe hacer de esta novela, qué significado asume en el contexto actual de una sociedad post-postmoderna. Nos sirven de ayuda algunas palabras esenciales que la propia autora destiló en la citada conferencia Pro e contro la bomba atomica. En este texto Elsa Morante, por vez primera públicamente, se adentra en las convulsiones de la sociedad contemporánea y en el acontecer del mundo, estamos a la altura - recordemos - de los candentes años sesenta. Se compromete ideológicamente; se pronuncia sobre el arte, y de manera específica sobre la función de la escritura (que no de la «literatura», pues su consideración de dicho término es peyorativa). Para ella «l'arte è il contrario della disintegrazione» y su función es »impedire la disintegrazione della coscienza umana, [...] restituirle [...] l'integrità del reale» (MORANTE, 2003: 1542). Si algo es evidente en nuestra sociedad, ahora galopantemente telemática, sometida a la revolución digital (amén de estar sometida a una pandemia global), es precisamente, su precariedad, la deshumanización, la desintegración, la abrupta mutación antropológica (por reutilizar un término pasoliniano). En 1924-1925, pronto hará un siglo, Ortega y Gasset publicó su famoso ensayo sobre La deshumanización del arte, en el que exponía el alejamiento del paradigma realista operado por las vanguardias. Pues bien, ahora no es el arte sino la sociedad, con su propia idiosincrasia, la que se está 'desrealizando', es la realidad (humana) del mundo la que se está desintegrando, fracturando vínculos, mentes y conciencias y, en ese contexto, los sentimientos — cuya expresión forma el armazón genuino y fiable de Aracoeli $^{47}$ — son precisamente la última frontera, lo que preserva nuestra humanidad, la parte fundamental que nos mantiene ligados, como individuos, a la citada realidad, a la vida auténtica. Por desgracia en esta obra, lucidísima, la tonalidad de dichos sentimientos es oscura, desesperanzada. Su senda, marcada por la memoria del dolor, conduce a un final inequívoco. Hay un párrafo, con un sustrato platónico y, al mismo tiempo, de evidente sincretismo de confesiones, con toques apocalípticos, que resume bien esa desesperanza. Con él concluimos:

Io, se fisso il cielo stellato fino in fondo, lo vedo tutto una fornace nera, che schizza braci e faville; e dove tutte le energie da noi spese nella veglia e nel sonno continuano a bruciare, senza mai consumarsi. Là dentro quella fornace planetaria, si sconta la nostra vita. È qua, dalle nostre vite,

46 Un parangón semejante ha expresado Cesare Cases, a propósito de L'isola d'Arturo, y de su protagonista Arturo: «Il parallelo tra questa infanzia e adolescenza dell'umanità è quelle del singolo è già in Vico e in Herder» (2008: 29). Elisa Martínez Garrido, por otra parte, considera que en Manuele hay una transferencia autobiográfica de preocupaciones existenciales morantianas y que la obra «può essere considerata, dunque, una metáfora del conflitto interiore del soggetto contemporaneo, la morte di una civiltà e il passaggio verso ciò che oggi conosciamo come globalizzazione»; Aracoeli, en fin, según esta estudiosa, sería una suerte de chivo expiatorio (MARTÍNEZ GARRIDO, 2016: 179-180). Profundiza monográficamente sobre el autobiografismo Ebru Sarikaya, (2017: passim).

47 «La trasformazione di Aracoeli, da creatura tenera, inocente e un po' magica, in una ninfomane pazza e dimentica del suo bambino diventa allora una sorta di vivente metafora di una realtà che ha smarrito ogni significato» (BERNABÒ, 2012: 264). 
che l'intero LÀ succhia tutta l'energia per i suoi moti. E allora io vorrei che venisse il Sabato della paga finale: dove l'intero firmamento si spegne (MORANTE, 1982: 292).

\section{REFERENCIAS BIBLIOGRÁFICAS}

Bernabò, Graziella (2012): La fiaba estrema. Elsa Morante tra vita e scrittura, Roma, Carocci.

Cartoni, Flavia (1999): La fantasía en la obra de Elsa Morante, Cuenca, Universidad de Castilla-La Mancha.

- (2015): «Al di là delle fonti. Elsa Morante tra letture, desideri e fantasia», Le fonti in Elsa Morante, eds. Enrico Palandri y Hanna Serkowska, Venezia, Edizioni Ca' Foscari, pp. 27-34 <https:// edizionicafoscari.unive.it/media/pdf/books/978-88-6969-045-7.pdf>, acceso: junio 2021.

CAses, Cesare ([1991] 2008): «Una pagina della Morante», L'Indice dei libri del mese, 5, pp. 28-29.

D'Angeli, Concetta (2003): «L'addio di Elsa Morante: Aracoeli», Leggere Elsa Morante. Aracoeli, La Storia e Il mondo salvato dai ragazzini, Roma, Carocci, pp. 16-80.

De Miguel y Canuto, Juan Carlos (2020): «Madama Pace cumple cien años. A vueltas con Seis personajes en busca de autor 1921-2021», Cuadernos de Filología Italiana, 27, pp. 221-239.

Fortini, Franco (1987): «Aracoeli», Nuovi saggi italiani, Milano, Garzanti, pp. 240-247.

Garboli, Cesare (1995): Il gioco segreto. Nove immagini di Elsa Morante, Milano, Adelfi.

García Melenchón, Francisco Javier (2016): La cultura española en la obra de Elsa Morante, Tesis doctoral, UAB.

GIDE, ANDRÉ ([1925] 2009): Les Faux- monnayeurs, Romans et récits, ouvres lyriques et dramatiques, eds. P. Masson-J. Claude Goulet et al., t.1, Paris, Gallimard.

Gragnolati, Manuele y Sara Fortuna, eds. (2009) : The Power of Disturbance. Elsa Morante's «Aracoeli», London, Legenda (MHRA \& Maney Publishing).

Holzhey, Christoph F. E. (2009): «'The Lover of a Hybrid': Memory and Fantasy in Aracoeli», The Power of Disturbance. Elsa Morante's «Aracoeli», eds. Manuele Gragnolati y Sara Fortuna, London, Legenda (MHRA \& Maney Publishing), pp. 41-58.

Homero (2015): Ilíada, trad. y ed. E. Crespo, rev. C. García Gual, Madrid, Gredos.

Martínez Garrido, Elisa (2016): I romanzi di Elsa Morante: scrittura, poesia ed etica, Lugano, Agorà.

Mengaldo, Pier Vincenzo ([1994] 2000): «Spunti per un'analisi linguistica dei romanzi di Elsa Morante», La tradizione del Novecento. Quarta serie, Torino, Bollati Boringhieri, pp. 147-168 (antes en Studi novecenteschi, XXI, 47-48).

Morante, Elsa (1982): Aracoeli. Romanzo,Torino, Einaudi.

- (2003): Opere, ed. Carlo Cecchi y Cesare Garboli, Milano, Mondadori, vol. 2.

- (2008): Araceli, trad. Ángel Sánchez-Gijón, ed. Flavia Cartoni, Madrid, Gadir.

SARIKAYA, Ebru (2017): «Aracoeli: romanzo di desolazione sociale o diario intimo dell'ultima Morante? Uno sguardo psicoanalitico all'universo di Elsa Morante», Diacritica III, pp. 55-70, <https:// diacritica.it/letture-critiche/aracoeli-romanzo-di-desolazione-sociale-o-diario-intimo-dellultima-morante.html>, acceso: junio de 2021.

Stellardi, GiusepPe (2014): «La fabbrica del tempo. Strutture della temporalità in Aracoeli», Cuadernos de Filología Italiana, 21, pp. 185-200.

West, Rebecca (2009): «Seeing and Telling: Anamorphosis, Relational Identity, and Other Perspectival Perplexities in Aracoeli», The Power of Disturbance. Elsa Morante's «Aracoeli», eds. Manuele Gragnolati y Sara Fortuna, London, Legenda (MHRA \& Maney Publishing), pp. 20-29.

Zagra, Giuliana (1993): «I manoscritti di Elsa Morante alla Biblioteca Nazionale di Roma», Elsa Morante. Mostra-Teatro-Incontri (Roma, 2 dicembre 1993 - 17 gennaio 1994), ed. Comune di Roma y Centro Sistema Bibliotecario [catálogo exposición]. 